\title{
Mindfulness Versus Cognitive Reappraisal: the Impact of Mindfulness-Based Stress Reduction (MBSR) on the Early and Late Brain Potential Markers of Emotion Regulation
}

\author{
Rebekah Jane Kaunhoven $^{1} \cdot$ Dusana Dorjee $^{2}$
}

Accepted: 5 July 2021 / Published online: 22 July 2021

(c) The Author(s) 2021

\begin{abstract}
Objectives A positive association between trait mindfulness and cognitive reappraisal has previously been found. Using event-related potentials (ERPs), we investigated the impact of an 8-week MBSR course on early and late stages of emotion regulation using mindfulness and reappraisal.

Methods Participants were allocated into an 8-week MBSR training group ( $n=14$ for task reports and self-reports; $n=10$ for ERPs) or a wait-list control group ( $n=15$ for task reports and self-reports; $n=11$ for ERPs). Pre and post the 8-week training, participants completed an affective picture viewing task and were instructed to regulate their responses to negative and neutral images using mindfulness, cognitive reappraisal and expressive suppression.

Results At post-test, only the training group showed significant improvements in self-reported trait mindfulness and trait cognitive reappraisal, together with improvements in the self-reported ability to employ mindfulness and cognitive reappraisal during the task. The training group showed decreased $200-280 \mathrm{~ms}$ positivity across all three strategies at post-test. The LPP did not change over time but overall showed more positive mean amplitudes to cognitive appraisal.

Conclusions These findings suggest that MBSR may adaptively modulate early attention deployment to emotional stimuli, but modulations of later stages of emotion processing may require more extensive mindfulness training. In addition, conscious employment of mindfulness may require less cognitive effort than cognitive reappraisal.
\end{abstract}

Keywords MBSR $\cdot$ Mindfulness $\cdot$ Cognitive reappraisal $\cdot$ Emotion regulation $\cdot$ ERP $\cdot$ Neuroscience

There is an ongoing debate about how to best define "emotions" (Izard, 2010). One common model proposed by Gross and Thompson (2007) defines emotions as the physiological, behavioural and subjective responses elicited to goal relevant stimuli. Emotion regulation is the management of all aspects of an emotional response (Gross, 1998). Adaptive methods of emotion regulation can effectively modulate the physiological responses to emotions and are linked with healthy social interactions, occupational achievements and general well-being (Aldao et al., 2009; Nelis et al., 2011a,

Rebekah Jane Kaunhoven

r.j.kaunhoven@bangor.ac.uk

1 School of Psychology, Bangor University, Bangor, Wales, UK

2 Psychology in Education Research Centre, Department of Education, University of York, Heslington, York, England, UK b). In contrast, maladaptive strategies can exacerbate illnessrelated physiological responses to emotions and are associated with conditions such as depression (Nelis, et al., 2011a, b).

There are many theories of emotion regulation (Koole, 2009); the process model of emotion regulation (Gross \& John, 2003) is a prominent theory which suggests that strategies which take effect early in emotional processing before an emotional response has been fully activated are called antecedent focused strategies. They are considered more effective than later, response-focused, strategies as they are able to modify both the subjective experience of an emotion and the behavioural response (Gross, 2002; Gross \& John, 2003). The most widely researched antecedent focused strategy is cognitive reappraisal which has been found to effectively reduce negative emotions by altering the meaning assigned to a stimulus through the active reinterpretation of a negative emotional situation into a positive one (Buhle et al., 2014; Goldin et al., 2008). 
Cognitive reappraisal has been found to be more effective than expressive suppression (Goldin et al., 2008; Haga et al., 2009), a response-focused strategy which is implemented after an emotional response has been activated, which aims to reduce negative affect through inhibiting the behavioural emotional response (Gross \& Thompson, 2007). Studies have found that expressive suppression can increase negative emotions (Haga et al., 2009; Roberts et al., 2008), possibly due to the discrepancy between the experienced emotion and the behavioural response to that emotion making the individual feel like they are acting in a disingenuous way (Gross \& John, 2003).

Over the last decade, mindfulness has gained attention as a possible adaptive antecedent focused method of emotion regulation (Goldin \& Gross, 2010; Teper et al., 2013). The well-being conducive effects of mindfulness-based approaches, mindfulness-based stress reduction (MBSR; Kabat-Zinn, 1990) and mindfulness-based cognitive therapy (MBCT; Segal et al., 2002) are relatively well-documented (e.g. Keng et al., 2011; Parsons et al., 2017). Debate remains regarding the specific definition of mindfulness (Hölzel et al., 2011); self-regulation of attention and the adoption of an accepting attitude towards experiences are considered integral components of mindfulness in the context of secular mindfulness-based approaches (Bishop et al., 2004). Mindfulness is thought to develop the ability to attend to the sensory aspects of stimuli whilst disengaging from the initial judgements and evaluations which are habitually assigned during perceptual processing (Shapiro et al., 2006). Through cultivation of a non-reactive, open and accepting attitude, one is able to reduce habitual reacting to experiences. This in turn frees up attentional resources to notice previously unattended aspects of experience which can result in a new perspective on them (Bishop et al., 2004; Shapiro et al., 2006).

There is no consensus on whether mindfulness regulates emotions via the recruitment of similar neural mechanisms to cognitive reappraisal or whether it is a fundamentally distinct strategy (Chiesa et al., 2013; Opialla et al., 2015). The mindful coping model (Garland et al., 2009) suggests that mindfulness and cognitive reappraisal have distinct but complementary mechanisms for regulating emotions. Mindfulness training is thought to facilitate cognitive reappraisal through developing a de-centred meta-cognitive awareness which assists reappraisal processes through initiating a disengagement from the initial automatic appraisal of the emotional situation (Garland et al., 2011). Mindfulness may, therefore, have an earlier impact on emotion processing than cognitive reappraisal. Mindfulness is thought to impact on emotion processing during the attention allocation stage of an emotional response (Goldin \& Gross, 2010); according to the process model of emotion regulation, this is an earlier stage than cognitive change, which cognitive reappraisal aims to impact (Gross \& John, 2003).
There seems to be overlap in brain areas activated by cognitive reappraisal and mindfulness. Both seem to regulate emotions through the recruitment of brain regions involved in top-down regulatory control, such as the medial prefrontal cortex, to down-regulate activity in the amygdala, which is involved in generating emotional responses (Goldin et al., 2008; Taylor et al., 2011). However, mindfulness may activate different neural mechanisms to those of cognitive reappraisal (Chiesa et al., 2013), some studies reported increased recruitment of bottom-up emotion regulation mechanisms after mindfulness training where a reduction in amygdala activity was associated with increased recruitment of brain regions linked with sensory awareness (Gard et al., 2012; Goldin \& Gross, 2010).

Event-related potentials (ERPs) can provide an assessment of the time course of an emotional response (Hajcak et al., 2010). Specifically, two ERP components, an early positivity in the $200-350 \mathrm{~ms}$ range and the late positive potential (LPP), have been shown to distinctively reflect the early and late stages of emotion processing (Dennis \& Chen, 2007; Hajcak \& Olvet, 2008). The early positivity in the $200-350 \mathrm{~ms}$ range, sometimes designated as the P200, indexes the initial allocation of attention resources during early stages of stimulus processing including stimulus discrimination, response selection and selective attention (Lutz et al., 2009; Mercado et al., 2009; Reva et al., 2014).

A study investigating the impact of cognitive reappraisal on early emotion processing found that whilst a more positive P200 was elicited when cognitive reappraisal was implemented to enhance a negative emotional response, no P200 modulation was observed when the instructions were to reduce the negative response (Wu et al., 2013). This suggests that the adaptive regulatory effects of cognitive reappraisal may only have an impact on later evaluative stages of emotional processing. Supporting this interpretation, Krompinger et al. (2008) also found that whilst the emotional content of stimuli had an impact between 225 and $325 \mathrm{~ms}$ after stimulus presentation, the regulatory effects of cognitive reappraisal did not have an impact until $325 \mathrm{~ms}$. To date, the impact of MBSR on early emotion processing has not been studied using ERPs. Given that mindfulness is thought to foster a disengagement from the automatic reactivity to all stimuli through facilitating the ability to pay attention to stimuli in a de-centred, open and accepting way (Shapiro et al., 2006), an attenuation of the early positivity could occur reflecting an increased ability to disengage from automatically reacting to stimuli during the earlier stages of an emotional response.

In contrast, the LPP ERP component indexes conscious emotion regulation of the later emotional response (Hajcak et al., 2010; Moser et al., 2009). This slow wave positivity starts approximately $300 \mathrm{~ms}$ after stimulus presentation and continues for several $1000 \mathrm{~ms}$; it is maximal at central/ 
parietal electrodes (Hajcak \& Olvet, 2008; Moser et al., 2010). The LPP is a measure of sustained attention towards stimuli of an emotional and arousing nature - a more positive LPP is elicited for emotional and highly arousing stimuli compared with neutral stimuli (Hajcak et al., 2010; Schupp et al., 2000). Hajcak and Nieuwenhuis (2006) found that the LPP elicited for unpleasant stimuli was attenuated when cognitive reappraisal was implemented compared to when emotions were unregulated; this was found in conjunction with a reduction in self-reported experience of negative emotions. Zhang et al. (2019b) found an attenuation of the LPP for emotional stimuli after a brief breath focused mindfulness meditation in comparison to passive viewing. In addition, high dispositional mindfulness has been associated with less positive LPPs to highly arousing negative and positive stimuli (Brown et al., 2013).

The current study investigated the impact of an MBSR course on the ability to regulate early and late emotional responses to negative images during an affective picture viewing task using three emotion regulation strategies: cognitive reappraisal, mindfulness and expressive suppression. MBSR was expected to facilitate the ability to regulate emotions using mindfulness and cognitive reappraisal given the documented overlap in top-down regulation pathways involved for both strategies (Modinos et al., 2010; Opialla et al., 2015) and correlational evidence on their positive relationship (Garland et al., 2011). Hence, an increase in self-reported scores of cognitive reappraisal and mindfulness compared with wait-list controls at post-test was expected. We predicted that mindfulness would impact both early and late stages of emotion processing resulting in an attenuation of both the early positivity in the 200-350 range and the LPP. We predicted that the effects of mindfulness on the early positivity might reflect a change in attentional deployment resulting from disengagement from the initial automatic appraisals, and thus be non-specific to the valence of stimuli. We expected decreased LPP amplitudes to negative stimuli in comparison to neutral stimuli which could reflect targeted conscious deployment of mindfulness as an emotion regulation strategy to reduce negative emotional responses. In contrast, for cognitive reappraisal, a reduction in the emotional reactions to negative images was expected only during the later stages of emotion processing, resulting in an attenuation of the LPP for negative stimuli. It was also predicted that the LPP elicited during the mindfulness condition would be less positive compared with cognitive reappraisal given that it may take effect earlier in emotion processing, and strategies which take effect earlier in emotion processing are associated with less cognitive effort (Sheppes \& Gross, 2011). For wait-list controls, no modulations of the early positivity and LPP for the three emotion regulation strategies were expected over time. Finally, we predicted that the most positive LPP would be for expressive suppression given that this strategy is ineffective at reducing physiological arousal to negative stimuli (Goldin et al., 2008; Gross \& John, 2003) and no LPP modulations were found during expressive suppression previously (Murata et al., 2013).

\section{Method}

\section{Participants}

Thirty-five participants were recruited from the local community through advertisements. All participants had normal or corrected to normal vision and reported having no previous mindfulness experience and no recent psychiatric or neurological problems. The participants were assigned to either an MBSR training group or a wait-list control group based on their availability; twenty participants were assigned to an MBSR training group (13 women, $M=25.5$ years, 19-36 years). Data from six participants in the training group was excluded from the analysis due to incompletion of the MBSR course. The remaining 14 participants in the MBSR training group (nine women, $M=27.3$ years, 21-36 years), except for one man, were right-handed according to the Edinburgh Handedness Inventory (Oldfield, 1971). Fifteen participants were assigned to the control group (nine women, $M=24.1$ years, 19-36 years), all were right-handed. For the 29 participants included in questionnaire analysis, $2 \times 2$ chi-square and independent $t$-tests did not reveal any significant differences in handedness, gender or age (all $p s>0.05$ ). Due to excessive artefacts in the EEG recording, data from four training group and four control group participants was excluded from the ERP analysis, and after this exclusion, there were still no significant differences in age, handedness or gender between groups $(p>0.05)$. Bangor University Ethics Committee approved the study prior to its start and all participants gave informed consent before participating. In recompense for participation in the study, training group participants received a free 8-week MBSR course and control group participants received either a 2-day intensive introduction to MBSR or a payment of $£ 30$.

\section{Procedures}

The study followed a non-randomised pre-post design with a control group. The training group received an MBSR course delivered by an MBSR trained counselling psychologist who had previously taught 30 mindfulness courses over a 6 -year period. The course consisted of eight weekly 2.5 -h group sessions and formal and informal individual home practice. For the formal practice, participants were asked to complete $45 \mathrm{~min}$ of guided meditations a day following meditation CDs. The informal practice involved applying the mindfulness principles whilst performing activities of daily living 
such as walking and showering. The control group received a 2-day intensive MBSR course after completion of the study.

Participants were tested before and after the 8 weeks of MBSR, and the control group was tested during the same time periods. At the beginning of the first testing session, participants provided written informed consent. The remaining procedures were identical for all sessions. Participants first completed self-report measures; following this, the participants washed their hair and were seated in a comfortable chair $1 \mathrm{~m}$ from the computer screen. A 64-channel electro cap was fitted and participants were verbally instructed to reduce movement artefacts by remaining still and focusing on the computer screen during the recording.

For the affective picture viewing task, a total of 105 negative images $(M$ valence $=3.13, M$ arousal $=5.52)$ and 105 neutral images $(M$ valence $=5.12, M$ arousal $=3.30)$ from the International Affective Picture System (IAPS; Lang et al., 2008) were selected. The IAPS images consisted of colour photographs of people, animals and natural landscapes. Negative and neutral images were rated as significantly different from each other in valence and arousal $(p<0.001)$. The negative images were significantly less arousing than the highly arousing images category of images used in the Brown et al. (2013) study $(p<0.05)$ as we chose images which we felt were more applicable to everyday experiences. The negative and neutral images were randomly distributed across three experimental blocks, 70 images ( 35 negative, 35 neutral) were presented in each block and images were not repeated to prevent habituation effects. The number of animals, people and natural scenes was evenly distributed across the three blocks and randomised within the blocks to reduce order effects. Independent $t$-tests revealed no significant difference for valence and arousal between the three blocks $(p>0.05)$. Each block lasted 6 min with a 5-min gap between blocks. The order of the three blocks was randomised and counterbalanced across participants and conditions.

In the affective picture viewing task, three experimental blocks were presented, and for each block, participants were instructed to employ one of the three emotion regulation strategies-mindfulness, cognitive reappraisal or expressive suppression-to regulate their emotional responses. Expressive suppression, a response focused strategy, was included as a maladaptive emotion regulation strategy condition to compare with mindfulness and reappraisal as adaptive strategies. The instructions for the strategies were as follows: in the mindfulness condition, participants were told to attend to the images or their experiences without analysis or judgement; cognitive reappraisal involved participants reinterpreting the images or the experiences to feel better; and expressive suppression involved suppression of the expression of an emotional response. In each experimental trial, a fixation cross appeared on the screen for $300 \mathrm{~ms}$ first, followed by a gap of $200 \mathrm{~ms}$, after which an image appeared on the screen for $1000 \mathrm{~ms}$. After the image was presented, there was a gap of $3000 \mathrm{~ms}$ to allow participants to employ the instructed emotion regulation strategy. During this gap, a reminder appeared on the screen that said either "suppress", "reappraise" or "be mindful" to remind the participant to use the correct strategy. Only one emotion regulation strategy was employed in each of the three blocks. The order in which emotion regulation strategies were employed was counterbalanced across participants to control for possible order and item-specific effects.

A manipulation check in the form of a self-report was administered after each block to record whether participants were employing the emotion regulation strategies correctly. Participants were asked to rate how well they thought they employed each strategy on a 7-point Likert scale ranging from 1 (not very well) to 7 (very well). They were also asked to describe how each strategy was employed. After completion of both testing sessions, participants were fully debriefed.

\section{Measures}

The Emotion Regulation Questionnaire (ERQ; Gross \& John, 2003) measured habitual use of cognitive reappraisal and expressive suppression. This questionnaire consists of 10 items, six items measure cognitive reappraisal and four items measure expressive suppression assessed on a 7-point Likert scale ranging from 1 (strongly disagree) to 7 (strongly agree). This ERQ has acceptable internal reliability for reappraisal $(\alpha=0.79)$ and suppression $(\alpha=0.73)$ in adults (Gross \& John, 2003).

The Five Facets of Mindfulness Questionnaire (FFMQ; Baer et al., 2006) measures self-reported mindfulness and consists of 39 items; eight items for each of for observing, describing, acting with awareness and nonjudging of inner experience facets, and seven items for nonreactivity to inner experience. The items are evaluated on a 5-point Likert scale ranging from 1 (never or very rarely true) to 5 (very often or always true). This self-report measure has been successfully used to assess changes in mindfulness over an 8-week MBSR course with healthy adults (Robins et al., 2012) and has acceptable $\alpha$ ranging from 0.72 to 0.92 (Baer et al., 2008).

\section{Data Analyses}

The EEG signal was recorded at a rate of $1 \mathrm{kHz}$ using Neuroscan SynAmps 1 amplifiers from $64 \mathrm{Ag} / \mathrm{AgCl}$ electrodes referenced to $\mathrm{Cz}$ and placed according to the international 10-20 system. Two electrodes were placed above and below the left eye to record eye movements and all electrode impedances were kept below $7 \mathrm{k} \Omega$. During data acquisition, the EEG signal was bandpass filtered online between 0.01 
and $200 \mathrm{~Hz}$. Movement artefacts were removed manually during visual inspection of the recording and then the signal was digitally filtered offline using a $30 \mathrm{~Hz}$ low pass zero phase shift filter with a 48 -dB/Oct slope. An ocular artefact correction algorithm was applied to regress out eye blinks, followed by epoching of the EEG data into $1.1 \mathrm{~s}$ sections starting $100 \mathrm{~ms}$ prior to stimulus onset and ending $1000 \mathrm{~ms}$ after. ERPs were time-locked to the onset of the images. Pre-stimulus activity was used for baseline correction to the stimulus epochs which were subsequently averaged for each of the three conditions and each participant, then rereferenced to the global field power reference. Finally, grand averages for each condition and group at pre-test and posttest were generated.

\section{Results}

\section{Changes in Self-reports of Mindfulness and Cognitive Reappraisal After MBSR}

The results from the FFMQ and ERQ were analysed for all participants (training group $n=14$, control group $n=15$ ), see Table 1. Eta-squared $\left(\eta^{2}\right)$ was calculated as an estimate of effect size and follow-up two-tailed paired samples $t$-tests were conducted on significant interactions with Cohens $d$ providing a measure of effect size. At post-testing, missing data was found in the FFMQ for two participants and in the task self-report for one participant. Little's test revealed that the data was missing at random (all $p \mathrm{~s}>0.05$ ) and missing values were calculated using the expectation maximisation algorithm. No extreme outliers ( $>3 \times$ interquartile range) were found in the data; however, moderate outliers were identified ( $>1.5 \times$ interquartile range), statistical analysis was run with inclusion and exclusion of outliers and when results did not significantly change outliers were kept in the data set to add power to the small sample size. When outliers did produce a marginal effect, results were reported with and without outliers.

Reliability of the FFMQ was acceptable (alpha coefficients range from 0.84 to 0.93 ). At pre-test, independent sample $t$-tests revealed that the control group had significantly higher scores on the acting with awareness subscale compared with the training group $(t(27)=-2.87, p=0.008$, $d=-1.06$ ); no significant group differences were found for the other FFMQ subscales (all $p$ s > 0.05). A 2 (group, training, control) $\times 2$ (time, pre-test, post-test) mixed factorial analysis of variance (ANOVA) was conducted on the total FFMQ scores and on each subscale. Significant main effects of time were found for total FFMQ scores $(F(1,27)=6.79$, $\left.p=0.015, \eta^{2}=0.14\right)$ and the subscale of observing $(F(1$, $27)=9.33, p=0.005, \eta^{2}=0.18$ ), scores significantly increased over time. For nonreactivity to inner experience, a significant main effect of time revealed that scores decreased
Table 1 A summary of the means and standard deviations for the total FFMQ scores, FFMQ subscales and ERQ subscales at pre-test and posttest for the training and control groups

\begin{tabular}{|c|c|c|c|c|c|c|c|c|}
\hline \multirow[b]{2}{*}{ Group } & & \multicolumn{3}{|c|}{ Pre-test } & \multicolumn{4}{|l|}{ Post-test } \\
\hline & & \multicolumn{2}{|l|}{$M$} & \multirow{2}{*}{$\frac{S D}{18.42}$} & \multicolumn{2}{|l|}{$M$} & \multicolumn{2}{|l|}{$S D$} \\
\hline \multirow{10}{*}{$\begin{array}{l}\text { Training group } \\
(n=14)\end{array}$} & Total FFMQ & 117.07 & & & $134.12 *$ & & 15.75 & \\
\hline & FFMQ subscales & & & & & & & \\
\hline & Observing & 25.43 & & 6.21 & $30.45 * *$ & & 5.41 & \\
\hline & Describing & 25.64 & & 5.02 & 28.22 & & 4.76 & \\
\hline & Acting with awareness & 20.57 & & 5.85 & $24.33 *$ & & 4.90 & \\
\hline & Nonjudging & 25.57 & & 6.51 & 28.57 & & 6.88 & \\
\hline & Nonreactivity & 19.86 & & 4.99 & 22.54 & & 3.77 & \\
\hline & ERQ subscales & & & & & & & \\
\hline & Cognitive reappraisal & 28.79 & & 4.15 & $32.21 *$ & & 4.25 & \\
\hline & Expressive suppression & 15.93 & & 5.77 & 13.64 & & 4.24 & \\
\hline \multirow{10}{*}{$\begin{array}{l}\text { Control group } \\
(n=15)\end{array}$} & Total FFMQ & 125.47 & & 12.47 & 122.53 & & 16.80 & \\
\hline & FFMQ subscales & & & & & & & \\
\hline & Observing & 24.60 & & 5.53 & 23.93 & & 7.06 & \\
\hline & Describing & 25.87 & & 5.83 & 25.07 & & 7.46 & \\
\hline & Acting with awareness & 26.53 & & 5.34 & $23.93 *$ & & 5.93 & \\
\hline & Nonjudging & 27.47 & & 6.31 & 28.00 & & 7.98 & \\
\hline & Non-reacting & 21.00 & & 3.36 & 21.60 & & 3.14 & \\
\hline & ERQ subscales & & & & & & & \\
\hline & Cognitive reappraisal & 29.20 & 5.49 & & & 28.27 & & 4.82 \\
\hline & Expressive suppression & 15.67 & 4.78 & & & 15.00 & & 3.53 \\
\hline
\end{tabular}

* Significant $p<.05, * *$ significant $p<.001$ 
over time $\left(F(1,27)=7.49, p=0.011, \eta^{2}=0.20\right)$. No significant main effect of group was found for total FFMQ or any other subscales FFMQ subscales (all $p s>0.05$ ). Significant group $\times$ time interactions were found for total FFMQ scores $\left(F(1,27)=13.61, p=0.001, \eta^{2}=0.29\right)$ and the two subscales of observing $\left(F(1,27)=15.91, p<0.001, \eta^{2}=0.30\right)$, and acting with awareness $(F(1,27)=23.71, p<0.001$, $\left.\eta^{2}=0.46\right)$. As expected, total FFMQ scores significantly increased for the training group after the MBSR course $(t(13)=-3.50, p=0.004, d=-0.93)$ along with scores for observing $(\mathrm{t}(13)=-4.79, p<0.001, d=-1.28)$, and acting with awareness $(t(13)=-3.61, p=0.003, d=-0.96)$. For the control group, no significant changes in total FFMQ scores $(t(14)=1.13, p=0.28, d=0.29)$ or scores for observing were found over time $(t(14)=0.69, p=0.50, d=0.18)$. Control group scores for acting with awareness significantly decreased over time $(t(14)=3.24, p=0.006, d=0.84)$, see supplementary materials.

Internal reliability for the cognitive reappraisal $(\alpha=0.74)$ and expressive suppression subscales $(\alpha=0.82)$ of the ERQ was acceptable. Independent sample t-tests revealed no significant group differences for scores of cognitive reappraisal and suppression at pre-test (all $p \mathrm{~s}>0.05$ ). A 2 (time, pretest, post-test) $\times 2$ (group, training, control) mixed factorial ANOVAs were conducted on each subscale. No significant main effects of group or time were found (all $p s>0.05$ ). However, a significant time $\times$ group interaction was found for cognitive reappraisal $\left(F(1,27)=6.74, p=0.015, \eta^{2}=0.19\right)$. Scores significantly increased for the training group after MBSR training $(t(13)=-2.95, p=0.011, d=-0.79)$; for the control group, no significant differences were found over time $(t(14)=0.77, p=0.45, d=0.20)$. No significant time $\times$ group interaction was found for expressive suppression over time (all $p \mathrm{~s}>0.05$ ), see supplementary materials. The distribution for the cognitive reappraisal subscale at post-test was slightly skewed, a Wilcoxon signed ranks test was conducted on the longitudinal data and the results confirmed the parametric analysis. Also, after removal of an outlier, the time $\times$ group interaction for cognitive reappraisal became marginal $\left(F(1,25)=35.57, p=0.056, \eta^{2}=0.13\right)$; however, follow-up $t$-tests confirmed the finding that cognitive reappraisal scores increased for the training group over time $(t(11)=-2.93, p=0.043, d=0.66)$.

A self-report form was administered during the task to check whether the strategies were employed correctly. The ratings from this self-report measure were not normally distributed and were therefore analysed using nonparametric tests. A Kruskal-Wallis test was performed on pre-test to see whether there were initial group differences. There was a significant group difference on cognitive reappraisal $\left(\chi^{2}(1)=7.18, p=0.007\right)$ with the control group having an initially higher reported ability to employ cognitive reappraisal. No significant pre-test differences were found between groups for the other strategies (all $p \mathrm{~s}>0.05$ ). Wilcoxon signed ranks tests were performed on the data to see how participant's use of the strategies changed over time. For the training group, there was a significant improvement in the ability to employ mindfulness $(\mathrm{Z}=-2.83, p=0.005$, $r=-0.53)$ and cognitive reappraisal $(Z=-2.03, p=0.042$, $r=0.38$ ) over time. The ability to employ suppression did not improve over time. For the control group, there was no significant improvement in the ability to employ any of the emotion regulation strategies (all $p \mathrm{~s}>0.05$ ). After removal of an outlier, the control group showed a significant decrease in cognitive reappraisal $(\mathrm{Z}=-2.42, p=0.015, r=-0.46)$, see supplementary materials.

It revealed that four training group participants and eight control group participants included in the ERP analysis did not correctly employ expressive suppression at either pre-test or post-test). Examples of the descriptions of how expressive suppression was implemented included treating the picture as an object, thinking the picture is not real or staged, the use of distraction by thinking of a song, relating the image to similar experiences and clearing the mind. The employment of the mindfulness and reappraisal strategies seemed to match the instruction provided. Examples of how cognitive reappraisal was implemented included changing the context of the picture so it was more positive such as thinking it was not real or finding ways to make the picture happier, such as seeing a sad man and thinking of giving him a hug. Examples of the descriptions given when implementing mindfulness included tuning into bodily sensations, experiencing emotion without analysing it or experiencing the emotion and then letting it go.

\section{Changes in 200-280 ms Positivity After MBSR}

The ERP analysis was conducted for 21 participants (training group $n=10$, control group $n=11$ ). Due to a high level of artefacts on electrode $\mathrm{PO} 4$ for one participant at pretest, this electrode was taken out of the analysis for this participant and replaced with values calculated using the expectation maximisation algorithm. Greenhouse-Geisser correction was applied when the assumption of sphericity was violated in the data analyses. The $\eta^{2}$ was calculated as an estimate of effect size, and significant main effects were followed up with pairwise comparisons. Two-tailed paired sample $t$-tests were conducted on significant interactions with Cohens $d$ providing a measure of effect size.

The grand mean global field power over the scalp was used to define the time interval for the mean amplitudes of the early positive component where the peaks were maximal; the time window was between 200 and $280 \mathrm{~ms}$. The signal was maximal at the PO4 and a cluster of parietal electrodes with maximum signal-P1, P3, P4 and PO4-were selected for analysis based on visual inspection of the peak 
waveforms. The early positivity component was classified as the mean amplitude between 200 and $280 \mathrm{~ms}$ averaged across these electrodes.

Baseline differences for the 200-280 ms amplitude were explored in a 2 (group, training, control) $\times 2$ (valence, negative, neutral) $\times 3$ (condition, mindfulness, reappraisal, suppression) mixed factorial ANOVA. No significant main effects of valence, condition or group were found (all $p \mathrm{~s}>0.05)$. There was a significant valence $\times$ condition interaction $\left(F(2,38)=4.78, p=0.014, \eta^{2}=0.04\right)$. For cognitive reappraisal, negative stimuli elicited a significantly more positive 200-280 ms component compared with neutral stimuli at baseline $(t(20)=3.09, p=0.006, d=0.67)$. No other significant interactions were found (all $p \mathrm{~s}>0.05$ ).

Longitudinal effects were investigated by conducting a 2 (group) $\times 2($ time $) \times 2$ (valence $) \times 3$ (condition) mixed factorial ANOVA. No main effects of time, valence, condition or group were significant (all $p \mathrm{~s}>0.05$ ). However, there was a significant time $\times$ group interaction $(F(1$, $19)=8.92, p=0.008, \eta^{2}=0.0 .18$ ) for the training group, the 200-280 ms component mean amplitude became significantly less positive over time across negative and neutral stimuli for the mindfulness, cognitive reappraisal and expressive suppression conditions $(t(9)=2.97, p=0.015$, $d=0.95$ ). No significant change in $200-280 \mathrm{~ms}$ component mean amplitude was observed for the control group over time $(t(10)=-1.51, p=0.16, d=-0.45)$ (see Figs. 1 and 2).

\section{Differences in LPP Between Cognitive Reappraisal and Mindfulness}

The LPP was maximal in the interval between 340 and $700 \mathrm{~ms}$ and parietal electrodes CPZ, P2 and PZ were selected for analysis based on visual inspection of the peak grand average ERP waveforms; the LPP was maximal at electrode P2. Greenhouse-Geisser correction was applied when the assumption of sphericity was violated. The LPP was classified as the mean amplitude between 340 and $700 \mathrm{~ms}$ averaged across these electrodes.

To check for pre-existing differences between groups and to assess whether neutral and negative stimuli together with the three emotion regulation conditions produced the expected differences, a 2 (valence, neutral, negative) $\times 3$ (condition, mindfulness; cognitive reappraisal, suppression) $\times 2$ (group, training, control) was conducted on pre-test data. There was a significant main effect of valence $\left(F(1,19)=20.11, p<0.001, \eta^{2}=0.14\right)$, with negative images eliciting a significantly more positive LPP then neutral images. There was a significant main effect of condition $\left(F(2,38)=3.46, p=0.042, \eta^{2}=0.09\right)$; pairwise comparisons revealed that the LPP elicited for a

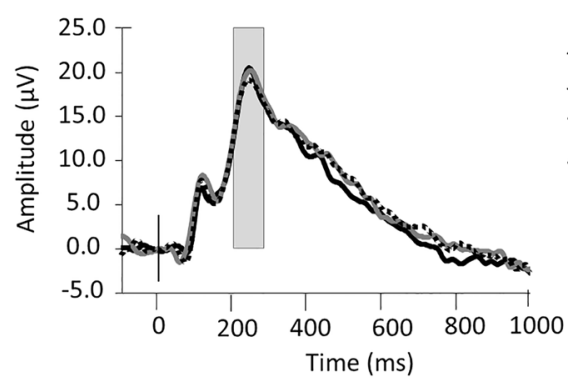

b

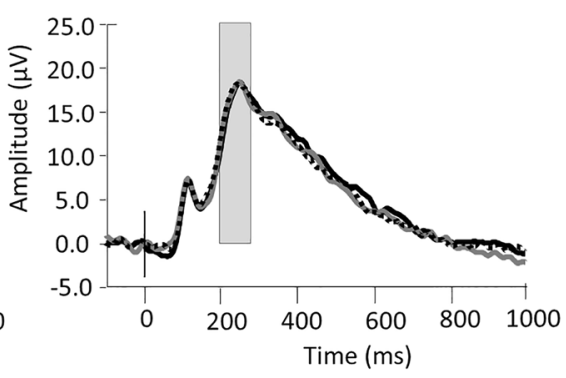

e

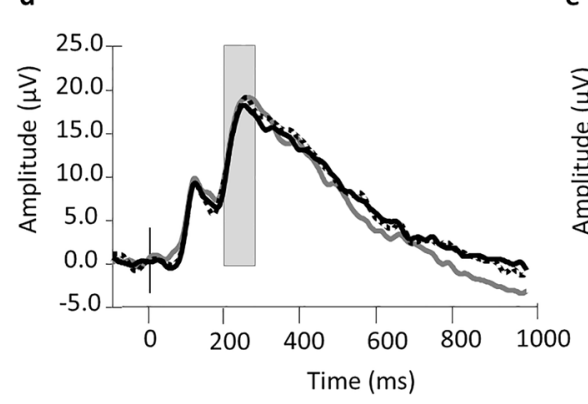

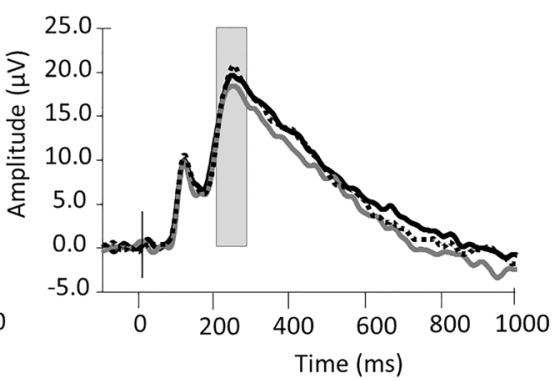

c

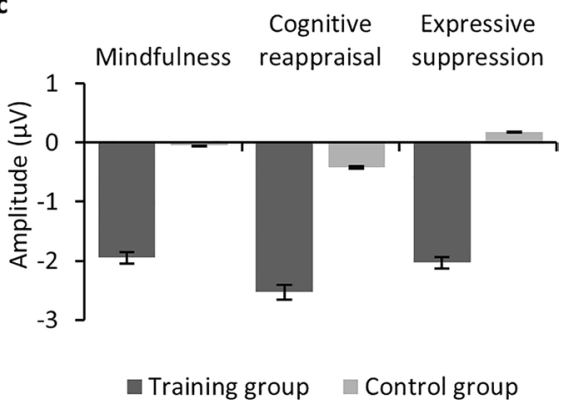

f

Mindfulness

Cognitive reappraisal

Expressive suppression
Fig. 1 The 200-280 ms component mean amplitude elicited for negatively valenced stimuli at maximal electrode PO4 for the mindfulness training group ( $n=9$ due to missing data on this electrode for one participant) at (a) pre-training and (c) post-training; and con- trol group $(n=11)$ at (d) pre-training and (e) post-training. c shows a graph with the difference between pre and post amplitude for each condition and $\mathbf{f}$ shows the legend for the ERP graphs 

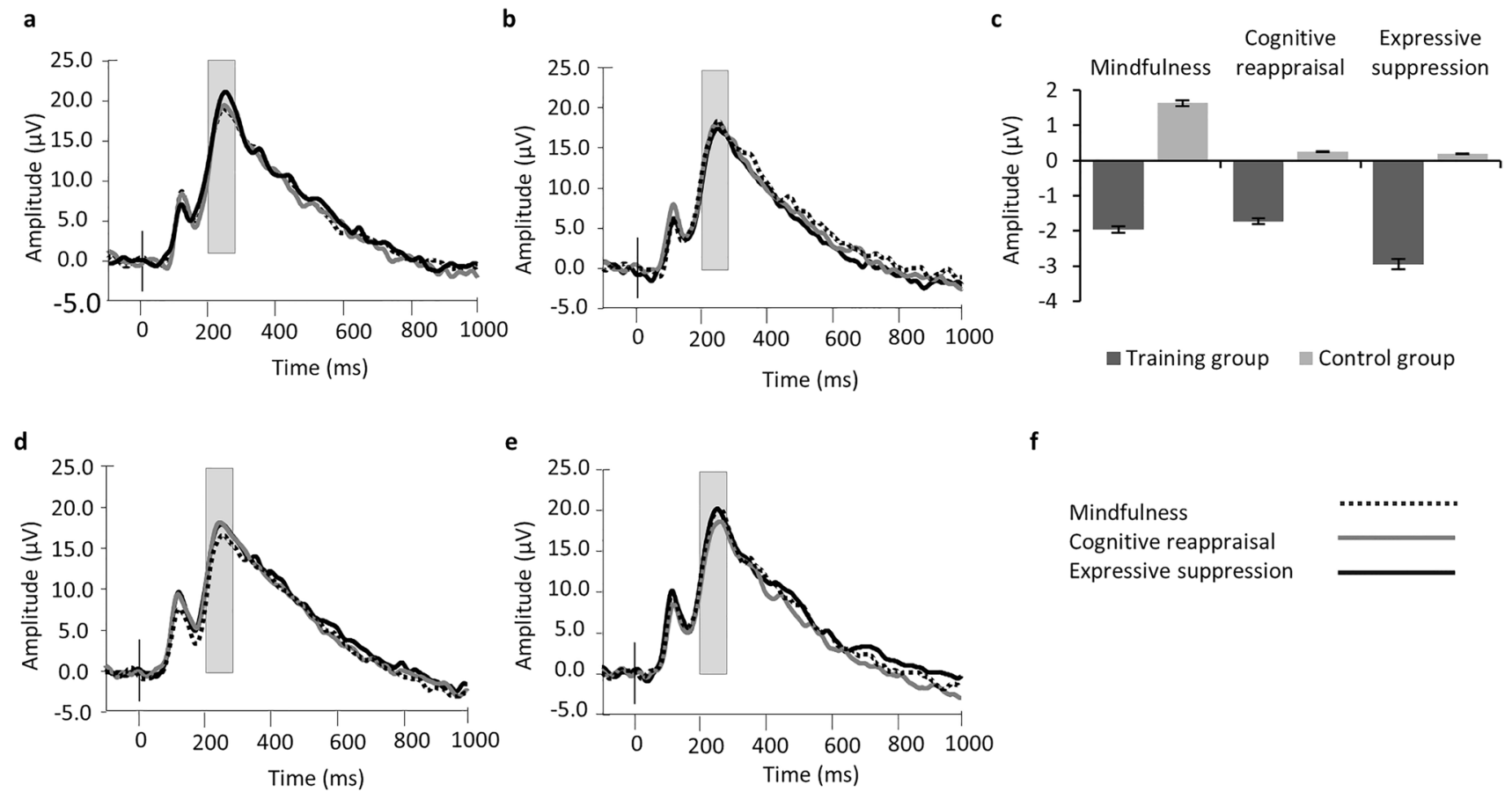

f

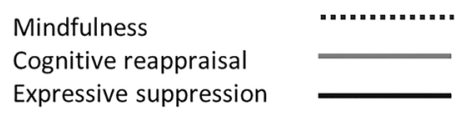

Fig. 2 The 200-280 ms component mean amplitude (200-280 ms) elicited for neutrally valenced stimuli at electrode PO4 for the mindfulness training group ( $n=9$ due to missing data on this electrode for one participant) at (a) pre-training and (b) post-training; and con- trol group $(n=11)$ at (d) pre-training and (e) post-training. $\mathbf{c}$ shows a graph with the difference between pre and post amplitude for each condition and $\mathbf{f}$ shows the legend for the ERP graphs cognitive reappraisal was more positive then the LPP elicited for suppression $(p=0.023)$. No significant group differences were found $(p>0.05)$. No other main effects or interactions were significant (all $p \mathrm{~s}>0.05$ ).

To assess longitudinal effects, a 2 (group) $\times 2$ (time) $\times 2$ (valence) $\times 3$ (condition) mixed factorial ANOVAs were conducted. There was a significant main effect of valence $\left(F(1,19)=38.85, p<0.001, \eta^{2}=0.08\right)$; the LPP was more positive for negative stimuli. There was a significant main effect of condition $\left(F(2,38)=8.29, p=0.001, \eta^{2}=0.08\right.$. and pairwise comparisons revealed that cognitive reappraisal was more positive then mindfulness $(p=0.011)$ and suppression $(p=0.001)$, but no difference between mindfulness and suppression was observed. There was also a significant valence $\times$ condition $\times$ group interaction $\left(F(2,38)=3.51, p=0.04, \eta^{2}=0.01\right)$; for both groups, there was a higher LPP for negative stimuli in the mindfulness and suppression condition; for the training group, there was no significant difference between mindfulness and cognitive reappraisal $(p=0.255)$. There were no other significant main effects of time or group and no significant interactions (all $p s>0.05$ ) (see Fig. 3 and 4).

\section{Discussion}

The aim of this study was to further the understanding of how 8 weeks of MBSR training modulates the neurocognitive mechanisms underlying the emotion regulation strategies of mindfulness, cognitive reappraisal and expressive suppression. The focus was on the 200-280 ms positivity and LPP component to assess the impact of these strategies on the early and late stages of emotion processing. The self-report findings showed improvements in trait mindfulness for the training group after the mindfulness training together with improvements in the habitual use of cognitive reappraisal. A significant improvement in the training group's self-reported ability to employ both mindfulness and cognitive reappraisal during the emotion regulation task was also found after the MBSR training. As expected, no changes in the habitual use of expressive suppression or the self-reported ability to use expressive suppression during the task were found in the training group. For the control group, no changes in self-reports of mindfulness, cognitive reappraisal or expressive suppression were observed except 
a

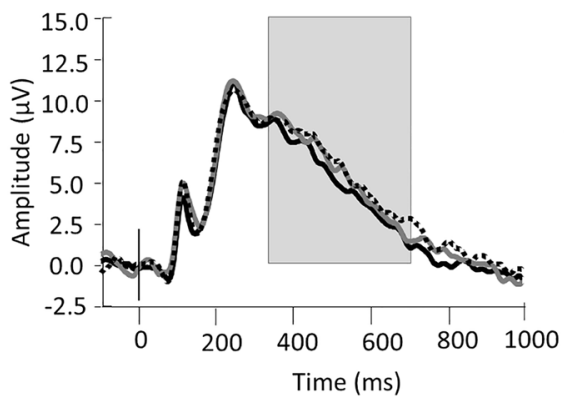

d

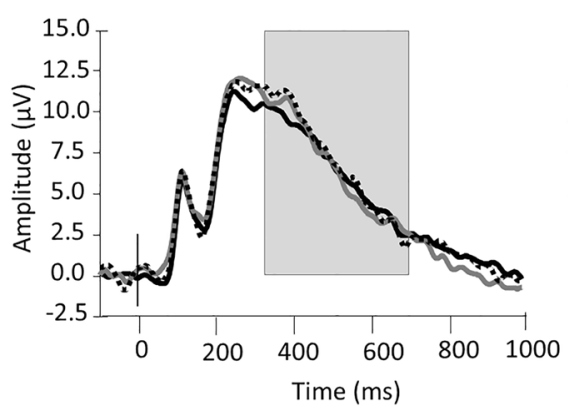

b

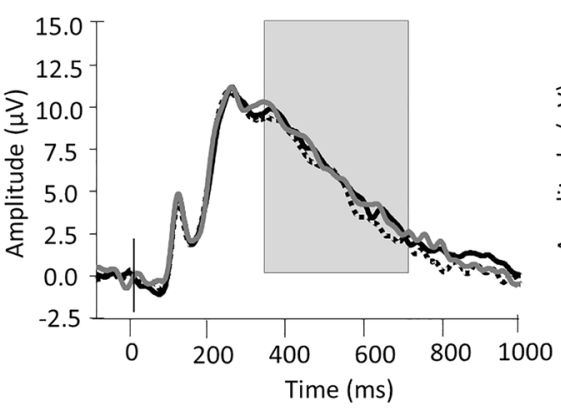

e

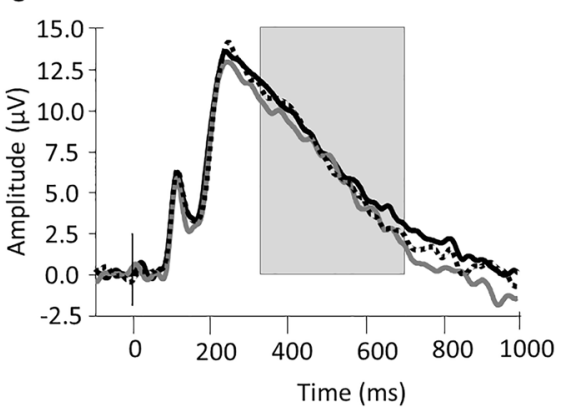

c

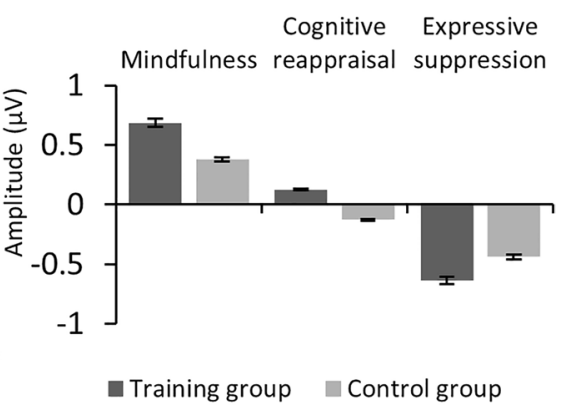

f

Mindfulness

Cognitive reappraisal

Expressive suppression
Fig. 3 The LPP amplitude (340-700 ms) elicited for negatively valenced stimuli at electrode $\mathrm{P} 2$ for the mindfulness training group $(n=10)$ at (a) pre-training and (b) post-training; and for the con- trol group $(n=11)$ at $(\mathbf{d})$ pre-training and (e) post-training. c shows a graph with the difference between pre and post amplitude for each condition and $\mathbf{f}$ shows the legend for the ERP graphs a

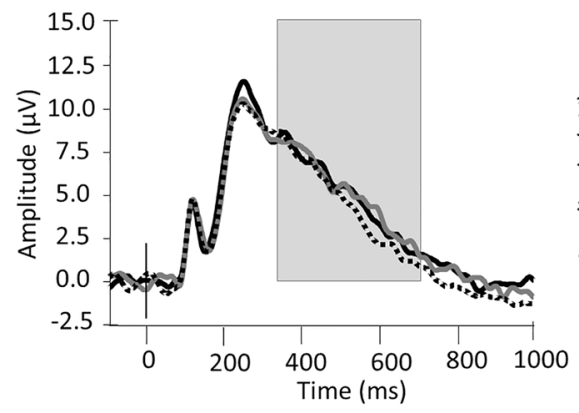

d

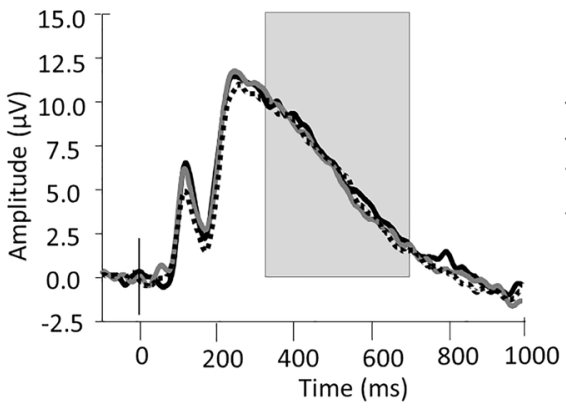

b
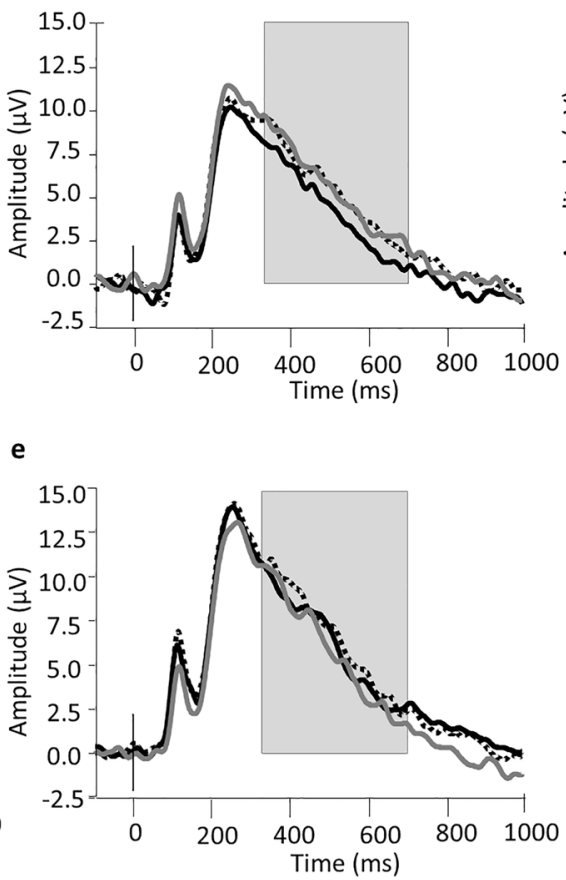

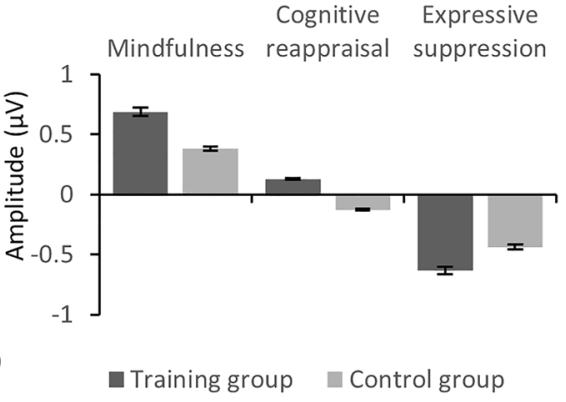

f

Mindfulness

Cognitive reappraisal Expressive suppression
Fig. 4 The LPP amplitude (340-700 ms) elicited for neutrally valenced stimuli at electrode $\mathrm{P} 2$ for the mindfulness training group $(n=10)$ at (a) pre-training and (b) post-training; and for the con- trol group $(n=11)$ at (d) pre-training and (e) post-training. c shows a graph with the difference between pre and post amplitude for each condition and $\mathbf{f}$ shows the legend for the ERP graphs 
for the mindfulness facet of acting with awareness which was found to decrease over time.

With regard to modulations of the $200-280 \mathrm{~ms}$ component, an attenuation was observed for the training group after the MBSR course and this was found for both negative and neutral stimuli, whilst the 200-280 ms component mean amplitude for the control group did not change over time. This 200-280 ms component attenuation was found across all three emotion regulation strategies after MBSR training and not solely during the implementation of the mindfulness strategy. Finally, the LPP findings revealed that for negative and neutral stimuli, the amplitude elicited for cognitive reappraisal was significantly more positive than the LPP elicited during the mindfulness and expressive suppression conditions; however, no group differences in the amplitude of the LPP were observed at the baseline or across time.

The self-report findings indicate that mindfulness training improves both state mindfulness, which is the ability to attend to stimuli in a mindful way at a specific time point (Brown \& Ryan, 2003) (as reflected by the self-report findings on how the strategies were applied in the experimental task) and trait mindfulness, a stable dispositional level of mindfulness which is present in daily life (Tang et al., 2015) (based on the FFMQ questionnaire). Similar self-reported improvements in state and trait cognitive reappraisal were also found after mindfulness training in our study. These findings are consistent with the assertions of the mindful coping model which suggests that mindfulness training improves the ability to implement cognitive reappraisal (Garland et al., 2009). Mindfulness training is thought to foster a perspective that emotions are brief passing states which can be accepted and then let go of. This may facilitate the disengagement from habitual appraisals and negative rumination and facilitate new appraisals of the experience (Garland et al., 2015).

Importantly, the attenuation of the $200-280 \mathrm{~ms}$ component for negative stimuli suggests that 8 weeks of MBSR training can impact upon the early stages of emotion processing and reduce the biased processing of negative stimuli. These ERP results support findings from behavioural studies which have found that a brief state of mindfulness can decrease the negativity bias (Kiken \& Shook, 2011) and 7 weeks of mindfulness training can improve the ability to inhibit the interference from emotional stimuli during cognitive processing (Ortner et al., 2007). An attenuation of the 200-280 ms component was also found for neutral stimuli after MBSR training. Positive components arising in the same time-range may reflect the initial automatic stages of attention resource allocation during early perceptual processing (Huang \& Luo, 2006; Stewart et al., 2010). MBSR training may therefore improve attention deployment efficiency and reduce the automatic mobilisation of attention resources towards all stimuli, possibly as the result of a reduction in the attention directed towards cognitive evaluative processes. This explanation is in line with previous findings that the P200 is less positive during breath focused episodes compared with mind wandering (a state where attention is directed towards thoughts and cognitive elaborations) (Braboszcz \& Delorme, 2011). The increased ability to attend to all stimuli in an open and non-elaborative way may make mindfulness a particularly effective emotion regulation strategy as it can act early in emotion processing and reduce the initial reactivity to emotional stimuli through changing the way stimuli are perceptually processed.

The finding that the 200-280 ms component attenuation was observed across all three emotion regulation strategies after MBSR training was unexpected and seemingly at odds with previous research which has found that cognitive reappraisal and expressive suppression take effect during later stages of emotion processing. Whilst cognitive reappraisal is an antecedent-focused strategy, its impact on emotion processing does not take effect until after the time window of the 200-280 ms component (Krompinger et al., 2008; Paul et al., 2013), with one study documenting the effects of cognitive reappraisal only $700 \mathrm{~ms}$ after stimulus onset (Paul et al., 2013). The self-report results from the task also suggested that participants were implementing cognitive reappraisal successfully during the task. One possibility is that the consistent decreases in 200-280 ms component amplitudes across conditions resulted from a trait change in the way stimuli were initially attended to after mindfulness training which generalised across the implementation of all emotion regulation strategies. This may influence the subjective conscious perception of implementing adaptive cognitive emotion regulation at later stages reflected in our study in the self-reported improvements in cognitive reappraisal observed after the mindfulness training.

The attenuation of the early positivity between 200 and $280 \mathrm{~ms}$ for expressive suppression would seem inconsistent with literature which suggests that suppression is a response focused strategy affecting the later stages of emotion processing (Gross \& John, 2003). The self-report data revealed that some participants used distraction rather than expressive suppression during the suppression condition in the task. Distraction is an antecedent focused strategy which has an impact during the early stages of an emotional response (Paul et al., 2013). In addition, no self-reported improvements in expressive suppression were observed after mindfulness training in our study. It is, therefore, unlikely that the 200-280 ms component modulation we observed was due to the implementation of expressive suppression.

It was also hypothesised that an attenuation of the LPP would be observed after MBSR training for both cognitive reappraisal and mindfulness compared with expressive suppression; and of particular interest were possible differences between these two strategies. The LPP is a 
measure of physiological arousal (Hajcak et al., 2010) and has been found to provide a sensitive marker of the impact of all three emotion regulation strategies on emotion processing (Eddy et al., 2015; Hajcak \& Nieuwenhuis, 2006; Murata et al., 2013). However, previous studies did not directly compare the impact of these three strategies on the LPP amplitude. A more positive LPP was elicited for cognitive reappraisal compared with the mindfulness strategy for both negative and neutral stimuli; mindfulness seems therefore to reduce the physiological arousal to emotions more successfully than cognitive reappraisal. Whilst both strategies have been found to effectively reduce the experience of negative affect after a mood induction task, cognitive reappraisal was associated with higher cognitive costs, as indexed by an increase in interference effects on a Stroop task (Keng et al., 2013, 2017). These differences in cognitive costs could occur because cognitive reappraisal involves elaborating upon negative experiences in order to change them into positive experiences (Chambers et al., 2009; Farb et al., 2012). Mindfulness, on the other hand, involves guiding attention towards experiences in the present moment, including unpleasant ones, and disengaging from cognitive elaborations which can take the focus of attention away from the present moment (Farb et al., 2012). The LPP finding is in line with suggestions that mindfulness might be a more adaptive emotion regulation strategy than cognitive reappraisal in some circumstances (Chambers et al., 2009; Farb et al., 2012).

The difference between the LPP elicited for cognitive reappraisal and mindfulness for negative stimuli was, however, observed for both groups and contrary to expectations the MBSR training did not have a modulatory effect on the amplitude of the LPP. Previously, a negative correlation between the scores of acting with awareness and the amplitude of the LPP has been found when studying the impact of dispositional mindfulness on the amplitude of the LPP (Brown et al., 2013) and meditators with at least 5 years of experience were found to elicit an attenuated LPP for negative stimuli compared with non-meditators (Sobolewski et al., 2011). In contrast, no modulation of the LPP to negative images was found after a brief induction of mindfulness (Eddy et al., 2015). The lack of compatibility in the results could be due to differences in the emotional pictures used-this current study was interested in studying how MBSR training modulates the response to naturalistic emotional images, and therefore, images of relatively low emotional arousal were used. Brown et al. (2013) used stimuli which were of a significantly more highly arousing nature. Therefore, it is possible that the more controlled modulation reflected by the LPP is needed only for strongly arousing stimuli and more naturalistic modulation of everyday unpleasant experiences occurs via earlier bottom-up processes as reflected by the $200-280 \mathrm{~ms}$ component shift in our study. In addition, previous studies which have found an effect of mindfulness on the LPP have either used individuals with high levels of dispositional mindfulness or experienced Buddhist meditators with at least 5 years of experience (Brown et al., 2013; Sobolewski et al., 2011). The participants in these studies would have had more developed meditation skills and so would have been able to regulate negative emotions in a different, and presumably more effective, way compared with the participants in the current study could after 8 weeks of mindfulness training. It is possible that this component is not a sensitive enough measure to reflect differences in emotion regulation after shorter mindfulness training and with more naturalistic, rather than more extreme emotional stimuli.

The LPP elicited for expressive suppression was less positive compared to cognitive reappraisal and no amplitude differences were observed between expressive suppression and mindfulness. An attenuation of the LPP has previously been found when participants were instructed to prepare to suppress the intensity of their emotional responses prior to stimulus onset (Moser et al., 2006), but these findings were different to our instructions which were more response focused and involved suppressing the expression of the emotional response. This therefore suggests that the way the instructions were interpreted could have impacted on the LPP findings. Findings from the manipulation check suggest that when instructed to employ expressive suppression, a considerable number of participants actually employed a range of other emotion regulation strategies, mostly distraction. Whilst both distraction and cognitive reappraisal have been found to modulate the LPP, distraction takes effect earlier in emotion processing than cognitive reappraisal (Paul et al., 2013; Sheppes \& Gross, 2011), and has been associated with less cognitive effort than cognitive reappraisal (Sheppes et al., 2009). Whilst in the long term, distraction may not be an effective strategy for regulating emotions (Thiruchselvam et al., 2011); in the short term, it could effectively reduce the physiological arousal to emotions (Kanske et al., 2010; Sheppes \& Gross, 2011).

We chose to use a block design for our emotion regulation task to increase the likelihood that participants were correctly implementing the emotion regulation strategies rather than combining multiple emotion regulation strategies or having difficulties in switching between different strategies (and the ERPs reflecting the switch cost) (Krompinger et al., 2008; Thiruchselvam et al., 2011; Zhang et al., 2019a). However, it is possible that this task design could have contributed to the higher LPP amplitudes for cognitive reappraisal in comparison to the other conditions. The cognitive reappraisal instructions may have increased cognitive demand as they required participants to attend to each image, evaluate it and then reinterpret it. In comparison, for the other two strategies, participants could have applied the same regulation 
approach regardless of the image content. This might have amplified the cognitive demand differences across the strategies in comparison to studies (Moser et al., 2009; Paul et al., 2013; Schönfelder et al., 2014) where the strategy instructions were randomised throughout the task.

\section{Limitations and Future Directions}

One of the limitations of the current study was that the attendance on the MBSR course and the number of hours of independent meditation practice carried out were much lower for the training group than expected. Most of the participants were students and therefore some missed training sessions either because they clashed with semester breaks or with course deadlines. Also, due to the low level of return on the time spent in practice self-report, the hours of meditation practice could not be analysed. It is for future studies to examine whether the amount of time spent in meditation practice has an effect on the electrophysiological correlates of emotion regulation. In addition, the sample size in our study was smaller than intended; this was partly due to artefacts in the EEG signal and partly due to non-completion of mindfulness training.

With regard to the experimental task, future studies could include an attend to images condition to control for trait baseline differences in habitual use of emotion regulation strategies in participants, and also explore interactions between these strategies and the effects of mindfulness training. This would require a larger participant sample due to variability of strategies participants may habitually employ.

This study evaluated changes in the time-course of emotion regulation after MBSR training using event-related potential indexes of early and late emotion processing recorded during employment of mindfulness, cognitive reappraisal and expressive suppression. Surprisingly, we have found evidence of early modulation of emotional responses during all three emotion regulation strategies. This suggests that MBSR training possibly resulted in the development of a trait-like adaptive modulation of early bottom-up emotion processes before more conscious modulation was applied. We have not found evidence of any of the three strategies impacting on later stages of emotion regulation differentially after mindfulness training. Overall, our findings suggest that mindful emotion regulation might be associated with a unique pattern of effective early regulation of emotional responses. This has implications for further research and for mindfulness training in groups which cannot effectively implement more conscious-controlled emotion regulation strategies.

Supplementary Information The online version contains supplementary material available at https://doi.org/10.1007/s12671-021-01692-8.
Acknowledgements This work was supported by the Centre for Mindfulness Research and Practice, and in particular, we would like to acknowledge David Shannon who delivered the MBSR programme. We would like to also acknowledge the contribution of the following master's students who assisted with the data collection: Franca Bühnemann, Shanker Venkatasubramanian and Mhairi Wilson.

Author Contribution DD devised the concept and design for the project, supervised data acquisition, supervised the analysis and interpretation of the data and edited and approved the final version of the manuscript. RK carried out the acquisition of the data as part of a master's project with contributions from other master's students, analysed and interpreted the data, wrote the manuscript and approved the final version of the manuscript.

\section{Declarations}

Ethics Approval This study was approved by the School of Psychology, Bangor University Ethics Committee. All participants provided written informed consent.

Conflict of Interest DD is a co-director of a community interest company providing training in mindfulness and well-being courses for schools. She does not receive royalties from these courses.

Open Access This article is licensed under a Creative Commons Attribution 4.0 International License, which permits use, sharing, adaptation, distribution and reproduction in any medium or format, as long as you give appropriate credit to the original author(s) and the source, provide a link to the Creative Commons licence, and indicate if changes were made. The images or other third party material in this article are included in the article's Creative Commons licence, unless indicated otherwise in a credit line to the material. If material is not included in the article's Creative Commons licence and your intended use is not permitted by statutory regulation or exceeds the permitted use, you will need to obtain permission directly from the copyright holder. To view a copy of this licence, visit http://creativecommons.org/licenses/by/4.0/.

\section{References}

Aldao, A., Nolen-Hoeksema, S., \& Schweizer, S. (2009). Emotionregulation strategies across psychopathology: A meta-analytic review. Clinical Psychology Review, 20, 217-237. https://doi. org/10.1016/j.cpr.2009.11.004

Baer, R. A., Smith, G. T., Hopkins, J., Krietemeyer, J., \& Toney, L. (2006). Using self-reports of assessment methods to explore facets of mindfulness. Sage Publications, 13(1), 27-45. https://doi.org/ 10.1177/1073191105283504

Baer, R. A., Smith, G. T., Lykins, E., Button, D., Krietemeyer, J., Sauer, S., Walsh, E., Duggan, D. D., \& Williams, J. M. G. (2008). Construct validity of the five facet mindfulness questionnaire in meditating and nonmeditating samples. Assessment, 15(3), 329-342. https://doi.org/10.1177/1073191107313003

Bishop, S. R., Lau, M., Shapiro, S., Carlson, L., Anderson, N. D., Carmondy, J., Segal, Z. V., Abbey, S., Speca, M., Velting, D., \& Devins, G. (2004). Mindfulness: A proposed operational definition. Clinical Psychology: Science and Practice, 11, 230-241. https://doi.org/10.1093/clinpsy/bph077

Braboszcz, C., \& Delorme, A. (2011). Lost in thoughts: Neural markers of low alertness during mind wandering. NeuroImage, 54(4), 3040-3047. https://doi.org/10.1016/j.neuroimage.2010.10.008 
Brown, K. W., Goodman, R. J., \& Inzlicht, M. (2013). Dispositional mindfulness and the attenuation of neural responses to emotional stimuli. Social Cognitive and Affective Neuroscience., 8(1), 93-99. https://doi.org/10.1093/scan/nss004

Brown, K. W., \& Ryan, R. M. (2003). The benefits of being present: Mindfulness and its role in psychological well-being. Journal of Personality and Social Psychology, 84(4), 822-848. https://doi. org/10.1037/0022-3514.84.4.822

Buhle, J. T., Silvers, J. A., Wager, T. D., Lopez, R., Onyemekwu, C., Kober, H., Weber, J., \& Ochsner, K. N. (2014). Cognitive reappraisal of emotion: A meta-analysis of human neuroimaging studies. Cerebral Cortex, 24(11), 2981-2990. https://doi.org/10.1093/ cercor/bht 154

Chambers, R., Gullone, E., \& Allen, N. B. (2009). Mindful emotion regulation: An integrative review. Clinical Psychology Review, 29(6), 560-572. https://doi.org/10.1016/j.cpr.2009.06.005

Chiesa, A., Serretti, A., \& Jakobsen, J. C. (2013). Mindfulness: Top-down or bottom-up emotion regulation strategy? Clinical Psychology Review, 33(1), 82-96. https://doi.org/10.1016/j.cpr. 2012.10.006

Dennis, T. A., \& Chen, C. C. (2007). Neurophysiological mechanisms in the emotional modulation of attention: The interplay between threat sensitivity and attentional control. Biological Psychology, 76(1), 1-10. https://doi.org/10.1016/j.biopsycho. 2007.05.001

Eddy, M. D., Brunyé, T. T., Tower-Richardi, S., Mahoney, C. R., \& Taylor, H. A. (2015). The effect of a brief mindfulness induction on processing of emotional images: An ERP study. Frontiers in Psychology, 6, 1391. https://doi.org/10.3389/fpsyg.2015.01391

Farb, N. A., Anderson, A. K., \& Segal, Z. V. (2012). The mindful brain and emotion regulation in mood disorders. Canadian Journal of Psychiatry, 57(2), 70-77. https://doi.org/10.1177/0706743712 05700203

Gard, T., Hölzel, B. K., Sack, A. T., Hempel, H., Lazar, S. W., Vaitl, D., \& Ott, U. (2012). Pain attenuation through mindfulness is associated with decreased cognitive control and increased sensory processing in the brain. Cerebral Cortex, 22(11), 2692-2702. https://doi.org/10.1093/cercor/bhr352

Garland, E. L., Farb, N. A., Goldin, R. P., \& Fredrickson, B. L. (2015). Mindfulness broadens awareness and builds eudaimonic meaning: A process model of mindful positive emotion regulation. Psychological Inquiry, 26(4), 293-314. https://doi.org/10.1080/10478 40X.2015.1064294

Garland, E. L., Gaylord, S., \& Park, J. (2009). The role of mindfulness in positive reappraisal. Explore: the Journal of Science and Healing, 5(1), 37-44. https://doi.org/10.1016/j.explore.2008.10.001

Garland, E. L., Gaylord, S. A., \& Fredrickson, B. L. (2011). Positive reappraisal mediates the stress-reductive effects of mindfulness: An upward spiral process. Mindfulness, 2(1), 59-67. https://doi. org/10.1007/s12671-011-0043-8

Goldin, P. R., \& Gross, J. J. (2010). Effects of mindfulness-based stress reduction (MBSR) on emotion regulation in social anxiety disorder. Emotion, 10(1), 83-91. https://doi.org/10.1037/a0018441.

Goldin, P. R., McRae, K., Ramel, W., \& Gross, J. J. (2008). The neural bases of emotion regulation: Reappraisal and suppression of negative emotion. Biological Psychiatry, 63(6), 577-586. https://doi. org/10.1016/j.biopsych.2007.05.031

Gross, J. J. (1998). The emerging field of emotion regulation: An integrative review. Review of General Psychology, 2(3), 271-299. https://doi.org/10.1037/1089-2680.2.3.271

Gross, J. J. (2002). Emotion regulation: Affective, cognitive, and social consequences. Psychophysiology, 39(3), 281-291. https://doi.org/ $10.1017 /$ S0048577201393198

Gross, J. J., \& John, O. P. (2003). Individual differences in two emotion regulation processes: Implications for affect, relationships and well-being. Journal of Personality and Social Psychology, 85(2), 348-362. https://doi.org/10.1037/0022_3514.85.2.348

Gross, J. J., \& Thompson, R. A. (2007). Emotion regulation: Conceptual foundations. In JJ Gross (Ed.), Handbook of emotion regulation. (pp. 3-24). Guilford Press

Haga, S. M., Kraft, P., \& Corby, E. K. (2009). Emotion regulation: Antecedents and well-being outcomes of cognitive reappraisal and expressive suppression in cross-cultural samples. Journal of Happiness Studies, 10(3), 271-291. https://doi.org/10.1007/ s10902-007-9080-3

Hajcak, G., MacNamara, A., \& Olvet, D. M. (2010). Event-related potentials, emotion, and emotion regulation: An integrative review. Developmental Neuropsychology, 35(2), 129-155. https:// doi.org/10.1080/87565640903526504

Hajcak, G., \& Nieuwenhuis, S. (2006). Reappraisal modulates the electrocortical response to unpleasant pictures. Cognitive, Affective, \& Behavioral Neuroscience, 6(4), 291-297. https://doi.org/10.3758/ CABN.6.4.291

Hajcak, G., \& Olvet, D. M. (2008). The persistence of attention to emotion: Brain potentials during and after picture presentation. Emotion, 8(2), 250-255. https://doi.org/10.1037/1528-3542.8.2.250

Hölzel, B. K., Lazar, S. W., Gard, T., Schuman-Olivier, Z., Vago, D. R., \& Ott, U. (2011). How does mindfulness meditation work? Proposing mechanisms of action from a conceptual and neural perspective. Perspectives on Psychological Science, 6(6), 537-559. https://doi.org/10.1177/1745691611419671

Huang, Y. X., \& Luo, Y. J. (2006). Temporal course of emotional negativity bias: an ERP study. Neuroscience Letters, 398(1-2), 91-96. https://doi.org/10.1016/j.neulet.2005.12.074

Izard, C. E. (2010). The many meanings/aspects of emotion: Definitions, functions, activation, and regulation. Emotion Review, 2(4), 363-370. https://doi.org/10.1177/1754073910374661

Kabat-Zinn, J. (1990). Full catastrophe living: Using the wisdom of your body and mind to face stress, pain and illness. Delacorte

Kanske, P., Heissler, J., Schönfelder, S., Bongers, A., \& Wessa, M. (2010). How to regulate emotion? Neural networks for reappraisal and distraction. Cerebral Cortex, 1379-1388. https://doi.org/10. 1093/cercor/bhq216

Keng, S. L., Robins, C. J., Smoski, M. J., Dagenbach, J., \& Leary, M. R. (2013). Reappraisal and mindfulness: A comparison of subjective effects and cognitive costs. Behaviour Research and Therapy, 51(12), 899-904. https://doi.org/10.1016/j.brat.2013.10.006

Keng, S. L., Smoski, M. J., \& Robins, C. J. (2011). Effects of mindfulness on psychological health: A review of empirical studies. Clinical Psychology Review, 31(6), 1041-1056. https://doi.org/ 10.1016/j.cpr.2011.04.006

Keng, S. L., Tan, E. L. Y., Eisenlohr-Moul, T. A., \& Smoski, M. J. (2017). Effects of mindfulness, reappraisal, and suppression on sad mood and cognitive resources. Behaviour Research and Therapy, 91, 33-42. https://doi.org/10.1007/s12671-016-0639-0

Kiken, L. G., \& Shook, N. J. (2011). Looking up: Mindfulness increases positive judgments and reduces negativity bias. Social Psychological and Personality Science, 2(4), 425-431. https://doi. org/10.1177/1948550610396585

Koole, S. L. (2009). The psychology of emotion regulation: An integrative review. Cognition and Emotion, 23(1), 4-41. https://doi.org/ 10.1080/02699930802619031

Krompinger, J. W., Moser, J. S., \& Simons, R. F. (2008). Modulations of the electrophysiological response to pleasant stimuli by cognitive reappraisal. Emotion, 8(1), 132-137. https://doi.org/10.1037/ 1528-3542.8.1.132

Lang, P. J., Bradley, M. M., \& Cuthbert, B. N. (2008). International affective picture system (IAPS): Affective ratings of pictures and instruction manual. Technical Report A-8. University of Florida

Lutz, A., Slagter, H. A., Rawlings, N. B., Francis, A. D., Greischar, L. L., \& Davidson, R. J. (2009). Mental training enhances attentional 
stability: Neural and behavioral evidence. The Journal of Neuroscience, 29(42), 13418-13427. https://doi.org/10.1523/JNEUR OSCI.1614-09.2009

Mercado, F., Carretié, L., Hinojosa, J. A., \& Penacoba, C. (2009). Two successive phases in the threat-related attentional response of anxious subjects: Neural correlates. Depression and Anxiety, 26(12), 1141-1150. https://doi.org/10.1002/da.20608

Modinos, G., Ormel, J., \& Aleman, A. (2010). Individual differences in dispositional mindfulness and brain activity involved in reappraisal of emotion. Social Cognitive and Affective Neuroscience, 5, 369-377. https://doi.org/10.1093/scan/nsq006

Moser, J. S., Hajcak, G., Bukay, E., \& Simons, R. F. (2006). Intentional modulation of emotional responding to unpleasant pictures: An ERP study. Psychophysiology, 43(3), 292-296. https://doi.org/10. 1111/j.1469-8986.2006.00402.x

Moser, J. S., Krompinger, J. W., Dietz, J., \& Simons, R. F. (2009). Electrophysiological correlates of decreasing and increasing emotional responses to unpleasant pictures. Psychophysiology, 46(1), 17-27. https://doi.org/10.1111/j.1469-8986.2008.00721.x

Moser, J. S., Most, S. B., \& Simons, R. F. (2010). Increasing negative emotions by reappraisal enhances subsequent cognitive control: A combined behavioral and electrophysiological study. Cognitive, Affective, \& Behavioral Neuroscience, 10(2), 195-207. https://doi. org/10.3758/CABN.10.2.195

Murata, A., Moser, J. S., \& Kitayama, S. (2013). Culture shapes electrocortical responses during emotion suppression. Social Cognitive and Affective Neuroscience, 8(5), 595-601. https://doi.org/ $10.1093 / \mathrm{scan} / \mathrm{nss} 036$

Nelis, D., Kotsou, I., Quoidbach, J., Hansenne, M., Weytens, F., Dupuis, P., \& Mikolajczak, M. (2011a). Increasing emotional competence improves psychological and physical well-being, social relationships, and employability. Emotion, 11(2), 354-366. https://doi.org/10.1037/a0021554

Nelis, D., Quoidbach, J., Hansenne, M., \& Mikolajczak, M. (2011b). Measuring individual differences in emotion regulation: The emotion regulation profile-revised (ERP-R). Psychologica Belgica, 51(1), 49-91. https://doi.org/10.5334/pb-51-1-49

Oldfield, R. C. (1971). The assessment and analysis of handedness: The Edinburgh inventory. Neuropsychologia, 9(1), 97-113. https://doi. org/10.1016/0028-3932(71)90067-4

Opialla, S., Lutz, J., Scherpiet, S., Hittmeyer, A., Jäncke, L., Rufer, M., Grosse Holtforth, M., Herwig, U., \& Brühl, A. B. (2015). Neural circuits of emotion regulation: A comparison of mindfulnessbased and cognitive reappraisal strategies. European Archives of Psychiatry and Clinical Neuroscience, 265(1), 45-55. https://doi. org/10.1007/s00406-014-0510-z

Ortner, C. N., Kilner, S. J., \& Zelazo, P. D. (2007). Mindfulness meditation and reduced emotional interference on a cognitive task. Motivation and Emotion, 31(4), 271-283. https://doi.org/10.1007/ s11031-007-9076-7

Parsons, C. E., Crane, C., Parsons, L. J., Fjorback, L. O., \& Kuyken, W. (2017). Home practice in Mindfulness-Based Cognitive Therapy and Mindfulness-Based Stress Reduction: A systematic review and meta-analysis of participants' mindfulness practice and its association with outcomes. Behaviour Research and Therapy, 95, 29-41. https://doi.org/10.1016/j.brat.2017.05.004

Paul, S., Simon, D., Kniesche, R., Kathmann, N., \& Endrass, T. (2013). Timing effects of antecedent-and response-focused emotion regulation strategies. Biological Psychology, 94(1), 136-142. https:// doi.org/10.1016/j.biopsycho.2013.05.019

Reva, N. V., Pavlov, S. V., Loktev, K. V., Korenyok, V. V., \& Aftanas, L. I. (2014). Influence of long-term Sahaja Yoga meditation practice on emotional processing in the brain: An ERP study.
Neuroscience, 281, 195-201. https://doi.org/10.1016/j.neuroscien ce.2014.09.053

Roberts, N. A., Levenson, R. W., \& Gross, J. J. (2008). Cardiovascular costs of emotion suppression cross ethnic lines. International Journal of Psychophysiology, 70(1), 82-87. https://doi.org/10. 1016/j.ijpsycho.2008.06.003

Robins, C. J., Keng, S. L., Ekblad, A. G., \& Brantley, J. G. (2012). Effects of mindfulness-based stress reduction on emotional experience and expression: A randomized controlled trial. Journal of Clinical Psychology, 68(1), 117-131. https://doi.org/10.1002/jclp. 20857

Schönfelder, S., Kanske, P., Heissler, J., \& Wessa, M. (2014). Time course of emotion-related responding during distraction and reappraisal. Social Cognitive and Affective Neuroscience, 9(9), 1310-1319. https://doi.org/10.1093/scan/nst116

Schupp, H. T., Cuthbert, B. N., Bradley, M. M., Cacioppo, J. T., Ito, T., \& Lang, P. J. (2000). Affective picture processing: The late positive potential is modulated by motivational relevance. Psychophysiology, 37(2), 257-261. https://doi.org/10.1111/1469-8986. 3720257

Segal, Z. V., Williams, J. M. G., \& Teasdale, J. D. (2002). Mindfulnessbased cognitive therapy for depression: A new approach to preventing relapse. Guilford Press.

Shapiro, S. L., Carlson, L. E., Astin, J. A., \& Freedman, B. (2006). Mechanisms of mindfulness. Journal of Clinical Psychology, 62(3), 373-386. https://doi.org/10.1002/jclp.20237

Sheppes, G., Catran, E., \& Meiran, N. (2009). Reappraisal (but not distraction) is going to make you sweat: Physiological evidence for self-control effort. International Journal of Psychophysiology, 71(2), 91-96. https://doi.org/10.1016/j.ijpsycho.2008.06.006

Sheppes, G., \& Gross, J. J. (2011). Is timing everything? Temporal considerations in emotion regulation. Personality and Social Psychology Review, 15(4), 319-331. https://doi.org/10.1177/10888 68310395778

Sobolewski, A., Holt, E., Kublik, E., \& Wróbel, A. (2011). Impact of meditation on emotional processing-A visual ERP study. Neuroscience Research, 71(1), 44-48. https://doi.org/10.1016/j.neures. 2011.06.002

Stewart, J. L., Silton, R. L., Sass, S. M., Fisher, J. E., Edgar, J. C., Heller, W., \& Miller, G. A. (2010). Attentional bias to negative emotion as a function of approach and withdrawal anger styles: An ERP investigation. International Journal of Psychophysiology, 76(1), 9-18. https://doi.org/10.1016/j.ijpsycho.2010.01.008

Tang, Y. Y., Hölzel, B. K., \& Posner, M. I. (2015). Traits and states in mindfulness meditation. Nature Reviews Neuroscience. https:// doi.org/10.1038/nrn.2015.7

Taylor, V. A., Grant, J., Daneault, V., Scavone, G., Breton, E., RoffeVidal, S., Courtemanche, J., Lavarenne, A. S., \& Beauregard, M. (2011). Impact of mindfulness on the neural responses to emotional pictures in experienced and beginner meditators. NeuroImage, 57(4), 1524-1533. https://doi.org/10.1016/j.neuroimage. 2011.06 .001

Teper, R., Segal, Z. V., \& Inzlicht, M. (2013). Inside the mindful mind how mindfulness enhances emotion regulation through improvements in executive control. Current Directions in Psychological Science, 22(6), 449-454. https://doi.org/10.1177/0963721413 495869

Thiruchselvam, R., Blechert, J., Sheppes, G., Rydstrom, A., \& Gross, J. J. (2011). The temporal dynamics of emotion regulation: An EEG study of distraction and reappraisal. Biological Psychology, 87(1), 84-92. https://doi.org/10.1016/j.biopsycho.2011.02.009

Wu, H., Tang, P., Huang, X., Hu, X., \& Luo, Y. (2013). Differentiating electrophysiological response to decrease and increase negative 
emotion regulation. Chinese Science Bulletin, 58(13), 1543-1550. https://doi.org/10.1007/s11434-013-5746-x

Zhang, J., Lau, E. Y. Y., \& Hsiao, J. H. (2019a). Using emotion regulation strategies after sleep deprivation: ERP and behavioral findings. Cognitive Affective \& Behavioral Neuroscience, 19, 283-295. https://doi.org/10.3758/ s13415-018-00667-y
Zhang, W., Ouyang, Y., Tang, F., Chen, J., \& Li, H. (2019b). Breathfocused mindfulness alters early and late components during emotion regulation. Brain and Cognition, 135. https://doi.org/10. 1016/j.bandc.2019.103585

Publisher's Note Springer Nature remains neutral with regard to jurisdictional claims in published maps and institutional affiliations. 